\title{
Correspondence
}

We welcome letters to the Editor concerning articles which have recently been published. Such letters will be subject to the usual stages of selection and editing; where appropriate the authors of the original article will be offered the opportunity to reply.

Letters should normally be under 300 words in length, double-spaced throughout, signed by all authors and fully referenced. The edited version will be returned for approval before publication.

\section{The image intensifier as an operating table: a dangerous practice}

Sir,

I would entirely endorse the sentiments of the cautionary paper in the January 2000 issue by Waseem and Kenny ${ }^{1}$ entitled 'The image intensifier as an operating table: a dangerous practice.'

Both my patient and I personally escaped serious injury merely by the good fortune that my drill bit failed to make contact with any high-voltage connection or other crucial part of the image intensifier as I drilled through the screen when attempting to lock a humeral intramedullary nail distally some two years ago. Even so the resulting hole in the screen resulted in an artefact on the VDU display until the screen was replaced at a cost of several thousands of pounds.

Using the screen of the image intensifier as an operating table is very convenient when good-quality images are required in the course of the operative procedure. Many so-called radiolucent tables produce quite a considerable reduction in the clarity of the image.

We have resolved this problem by using a simple domestic polyethylene chopping board such as may be purchased at most supermarkets or kitchen shops at a cost of less than $£ 5$.

The chopping board is laid over the screen, effectively protecting it from harm while retaining a clear image. We have been using the chopping board for the past two years and have had no near misses during this time.

M. G. MATTHEWS, MA, FRCS

Wycombe Hospital

South Bucks NHS Trust, UK

1. Waseem M, Kenny NW. The image intensifier as an operating table: a dangerous practice. J Bone Joint Surg [Br] 2000;82-B:95-6.

Authors' reply:

Sir,

We thank Mr Matthews for his letter, which proves our point. We also note the excellent suggestion put forward, although it may not always be possible to retain the quality of image which may depend on the quality of polyethylene.

M. WASEEM, FRCS

Tameside General Hospital

Ashton-under-Lyne, UK

N. W. KENNY, FRCS Orth

Manchester Royal Infirmary, UK.

(C)2000 British Editorial Society of Bone and Joint Surgery

0301-620X/00/511311 \$2.00

J Bone Joint Surg [Br] 2000;82-B:774-6.
Sir,

I read with interest the paper in the January issue by Waseem and Kenny ${ }^{1}$ entitled 'The image intensifier as an operating table: a dangerous practice. The report suggests that the $\mathrm{C}$-arm image intensifier is often used as an operating table, particularly in hand surgery, for easy positioning and clearer quality of the image. I wonder if this practice is uniform in all hand surgery units in the UK.

When the C-arm of the image intensifier is used in such a mode, the surgeon has an obligation to use it carefully, particularly when one employed sharp instruments such as wires and drills. I would suggest that a radiotranslucent attachment to the $\mathrm{C}$-arm as a work top should be used when the $\mathrm{C}$-arm is used in this way.

S. B. TIBREWAL, FRCS

Manchester Royal Infirmary

Manchester, England.

1. Waseem M, Kenny NW. The image intensifier as an operating table: a dangerous practice. J Bone Joint Surg [Br] 2000;82-B:95-6.

Authors' reply:

Sir,

We must point out that the suggestion that the image intensifier is often used as an operating table in orthopaedic practice in the UK was based on informal inquiries and not on the basis of a properly conducted survey.

As regards to use of a radiotranslucent attachment, we feel that it is a good suggestion, but it is only a few millimetres thick and would provide very little protection. It may also alter the quality of the image obtained.

\section{WASEEM, FRCS}

Tameside General Hospital

Ashton-under-Lyne, UK.

N. W. KENNY, FRCS Orth

Manchester Royal Infirmary, UK.

Sir,

We endorse the view of Waseem and Kenny in the January 2000 issue entitled 'The image intensifier as an operating table: a dangerous practice ${ }^{1}$ that the collimator of the image intensifier should not be used as an operating table. Adequate surgical skills and the use of a radiolucent table would appear to solve the problem of potential damage to the image intensifier. The use of the image intensifier in this configuration (collimator below the patient and source above), however, is against the advice of our Trusts Ionising Radiation Regulations (1995). ${ }^{2}$ In order to achieve improved images in the recommended configuration, it is necessary to lower the collimator close to the fracture. This obscures the surgeon's view, and places him in the cone of radiation. Van Staden et $\mathrm{al}^{3}$ investigated the radiation exposure to a "phantom surgeon' standing in a position as if about to operate on a simulated arm, with the C-arm in the two configurations. It was found that with the collimator above the patient there was increased exposure to the thyroid $(0.38 \mathrm{mGy} / \mathrm{hr})$ and eye $(0.35 \mathrm{mGy} / \mathrm{hr})$ when compared with the collimator below the patient $(0.26 \mathrm{mGy} / \mathrm{hr}$ and $0.19 \mathrm{mGy} / \mathrm{hr})$, respectively. The radiation exposures to the hands $(1.6 \mathrm{mGy} / \mathrm{hr})$, groin $(0.0 \mathrm{mGy} / \mathrm{hr})$ and feet $(0.2 \mathrm{mGy} / \mathrm{hr})$ were similar in both configurations. While the 
Ionising Radiation Regulations are designed to protect the theatre staff and patient, they may come into conflict with the requirements of the surgeon in the fixation of fractures of the hand and wrist. The study demonstrated that the use of the collimator below the patient reduces the exposure of the eyes and thyroid of the surgeon to ionising radiation, while allowing an adequate surgical field. For fixation of fractures of the hand and wrist we would therefore suggest that the use of a radiolucent table and the collimator below the patient improves imaging, makes operating easier, and reduces radiation exposure.

I. T. SHARPE, BSc, FRCS

G. VAN STADEN, MB BS

Princess Elizabeth Orthopaedic Centre

Exeter, UK.

1. Waseem M, Kenny NW. The image intensifier as an operating table: a dangerous practice. J Bone Joint Surg [Br] 2000;82-B:95-6.

2. Royal Devon and Exeter Healthcare Trust. Rules on the use of ionising radiation. 1995.

3. Van Staden G, Farrant K, Richards R, Bunker T. Image intensifier position for hand and wrist fractures. Injury 2000;31:351-2.

\section{Authors' reply:}

\section{Sir,}

We agree with Mr Sharpe and Dr Van Staden regarding the exposure to radiation. One of us (MN) has already discussed exposure to the thyroid and how to avoid it. ${ }^{1}$ It has also been shown that the maximum monthly extremity dosage received by an orthopaedic surgeon is $6 \mathrm{~m} \mathrm{~Sv}$. This is approximately half the recommended maximum, ${ }^{2}$ but we must still try to reduce it. We also agree that under certain circumstances this is unavoidable in order to maintain quality.

M. WASEEM, FRCS

Tameside General Hospital

Ashton-under-Lyne, UK

N. W. KENNY, FRCS Orth

Manchester Royal Infirmary,

U.K.

1. Waseem M, Gleasure A, Canty S, Pool AS. Back to front; we lead. Orthop Update (India) 1997;7:152-3.

2. Smith GL, Wakeman R, Briggs TWR. Radiation exposure of orthopaedic trainees: quantifying the risk. $J R$ Coll Surg Edin 1996;41:132-4.

\section{Intra-articular steroids after arthroscopy for osteoarthristis of the knee}

Sir,

We read with interest the annotation by Gosal, Jackson and Bickerstaff ${ }^{1}$ in the November 1999 issue entitled 'Intra-articular steroids after arthroscopy for osteoarthritis of the knee.' We agree that there is certainly good scientific evidence for an immunosuppressive effect of intra-articular steroids. There is similarly reasonable evidence for the harmful effect of an overdose. The basic scientific evidence presented for the effect of corticosteroids on articular cartilage is conflicting.

The clinical evidence for the risk of infection is potentially misleading. In the large studies presented, there appears to be a higher incidence of septic arthritis in the steroid-treated groups. These studies are all uncontrolled, retrospective and heterogeneous. Furthermore, even the authors agree that this evidence is tainted with confounding variables such as the instrumentation used, the length of the procedure and previous surgery. Not one statistically significant result is presented. The authors' 'recent experience' lacks scientific method. By way of comparison, three papers suggesting a beneficial clinical effect of corticosteroids, including one using a double-blind study, are dismissed in a single sentence.

We would agree with the authors that the data presented raise concerns. Until there are results from a multicentre, randomised prospective study, however, the case against intra-articular steroids and arthroscopy remains unproven. Furthermore, we believe that the authors have drawn conclusions which have not been supported by the evidence given. This is potentially harmful to the medical profession since articles like this may be consulted in the development of national guidelines for clinical practice. Unless published articles are truly evidence-based, clinical freedom may be unnecessarily compromised.

W. R. C. PECKETT, BSc, FRCS

A. BUTLER-MANUEL, FRCS

Conquest Hospital

Hastings, UK.

1. Gosal HS, Jackson AM, Bickerstaff DR. Intra-articular steroids after arthroscopy for osteoarthritis of the knee. J Bone Joint Surg [Br] 1999;81-B:952-4.

\section{Authors' reply:}

Sir,

We are grateful to Messrs Peckett and Butler-Manuel for their interest in our article. We have presented a balanced appraisal of the effects of corticosteroids on articular cartilage. We are not aware of any papers suggesting a beneficial clinical effect of corticosteroids and we are a little confused as to which papers they are referring. The animal studies showing some benefit of steroids (Pelletier and Martel-Pelletier, and Pelletier et $\mathrm{al}^{2}$ ) are, rather than being dismissed, given adequate coverage. There are no clinical, double-blind randomised studies on this matter. We believe that to do such a study, in the face of clinical observational evidence, would raise some very serious ethical issues. If they are aware of such investigations or are planning to undertake one, we would be very interested. We believe that it would be very difficult to gain approval of an ethical committee for such a study as clinical evidence points to the deleterious effects of intraarticular corticosteroids in the osteoarthritic knee after arthroscopy. Since our article was published, we have become aware of another medicolegal case of septic arthritis following the use of corticosteroids in the osteoarthritic knee after arthroscopy.

A show of hands at a recent meeting of the British Association of Surgery of the Knee showed almost unanimous approval of the view that steroids should not be used at the time of arthroscopy because of the potential complications of septic arthritis (personal communication to DRB). Most knee surgeons do not use steroids at the time of arthroscopy for osteoarthritic knees, and the reason for our annotation was to draw attention to the potential problems for non-specialists in this field. We believe that our experience may be the tip of the iceberg and instead of jeopardising clinical freedom it should forewarn our colleagues of the hazards of such clinical practice and the potentially serious consequences for our patients.

H. S. GOSAL, FRCS Orth

A. M. JACKSON, FRCS

D. R. BICKERSTAFF, MD, FRCS, FRCS Ed

St George's Hospital

London, UK. 
1. Pelletier JP, Martel-Pelletier J. Protective effects of corticosteroids on cartilage lesions and osteophyte formation in the Pond-Nuki dog model of osteoarthritis. Arthritis Rheum 1989;3:818-93.

2. Pelletier JP, Mineau F, Raynauld JP, et al. Intra-articular injections with methylprednisolone acetate reduce osteoarthritic lesions in parallel with chondrocyte stromelysin synthesis in experimental osteoarthritis. Arthritis Rheum 1994:37:414-23.

\section{Intraoperative bacterial contamination in operations for joint replacement}

Sir,

I read with interest the article by Davis et $\mathrm{al}^{1}$ in the September 1999 issue entitled 'Intraoperative bacterial contamination in operations for joint replacement.'

They emphasised several important points to help to prevent contamination of the surgical wound such as the wearing of waterproof gowns by the surgeon, changing gloves after draping and the use of a scrubbed 'leg-holder'. They did not comment on the use of plastic incision drapes or their method of application. I would be interested to know if these were routinely used in their series and how they were applied.

During joint replacement surgery I make an effort to isolate the operative wound from the patient's skin by the use of plastic incision drapes (Ioban; 3M, Minneapolis, Minnesota). In order to ensure that the drape sticks to the skin and remains adherent during the operation I de-fat the skin before painting with isopropyl alcohol, and then use a single-step iodine and alcohol preparation (Duraprep; 3M) before the application of the plastic incision drape. Using this technique I have been able to maintain a tight seal of the drape to the patient's skin. I believe that this method greatly reduces the risk of contamination of the wound from the patient's skin.

\section{A. GUTOW, MD}

Emory University School of Medicine

Atlanta, Georgia, USA.
1. Davis N, Curry A, Gambhir AK, et al. Intraoperative bacterial contamination in operations for joint replacement. J Bone Joint Surg [Br] 1999;81-B:886-9.

\section{Authors' reply:}

Sir,

We wish to thank Dr Gutow for his comments on our paper and clarify the method of preparing the patients' skin before surgery. All patients are showered on the day of surgery to degrease the skin. Aqueous betadine is used for preparation of the skin. Some of the patients are prepared in the anaesthetic room as well as in theatre, which significantly reduces the contamination of the overgloves worn during the final preparation in theatre. We do not use alcoholic solutions to avoid the risk of pooling and the potential for fire hazard. The skin is allowed to dry before the application of the plastic incision drape. We routinely use the Ioban drape described by Dr Gutow. This is very adhesive and we have not had any problems with loss of contact of the incision drape by this method.

Fairclough, Johnson and Mackie ${ }^{1}$ maintain that it is not the surface bacteria which cause the contamination of the wound but those which lie deeper in the hair follicles and sebaceous glands and are exposed by the initial incision. They recommend that an Ioban drape is positioned over the intended incision site for 24 hours before surgery to eradicate these.

N. DAVIS, FRCS (Tr \& Orth)

A. K. GAMBHIR, FRCS

P. R. KAY, FRCS G

University of Manchester, North Manchester General Hospital Manchester, UK.

1. Fairclough JA, Johnson D, Mackie I. The prevention of wound contamination by skin organisms by the preoperative application of an iodophor impregnated plastic adhesive drape. J Int Med Res 1986;14:105-9. 